\title{
Twin CHCH Proteins, CHCHD2, and CHCHD10: Key Molecules of Parkinson's Disease, Amyotrophic Lateral Sclerosis, and Frontotemporal Dementia
}

\author{
Yuzuru Imai ${ }^{1,2, *(\mathbb{D}) \text {, Hongrui Meng }}{ }^{3}$, Kahori Shiba-Fukushima ${ }^{4}$ and Nobutaka Hattori ${ }^{1,2,3,4, *}$ \\ 1 Department of Research for Parkinson's Disease, Juntendo University Graduate School of Medicine, \\ Tokyo 113-8421, Japan \\ 2 Department of Treatment and Research in Multiple Sclerosis and Neuro-intractable Disease, \\ Juntendo University Graduate School of Medicine, Tokyo 113-8421, Japan \\ 3 Department of Neurology, Juntendo University Graduate School of Medicine, Tokyo 113-8421, Japan; \\ hmon@juntendo.ac.jp \\ 4 Department of Neurodegenerative and Demented Disorders, Juntendo University Graduate School of \\ Medicine, Tokyo 113-8421, Japan; kshiba@juntendo.ac.jp \\ * Correspondence: yzimai@juntendo.ac.jp (Y.I.); nhattori@juntendo.ac.jp (N.H.); \\ Tel.: +81-3-6801-8332 (Y.I.); +81-3-5802-2731 (N.H.)
}

Received: 7 February 2019; Accepted: 17 February 2019; Published: 20 February 2019

\begin{abstract}
Mutations of coiled-coil-helix-coiled-coil-helix domain containing 2 (CHCHD2) and 10 (CHCHD10) have been found to be linked to Parkinson's disease (PD), amyotrophic lateral sclerosis (ALS), and/or frontotemporal lobe dementia (FTD). CHCHD2 and CHCHD10 proteins, which are homologous proteins with $54 \%$ identity in amino acid sequence, belong to the mitochondrial coiled-coil-helixcoiled-coil-helix $(\mathrm{CHCH})$ domain protein family. A series of studies reveals that these twin proteins form a multimodal complex, producing a variety of pathophysiology by the disease-causing variants of these proteins. In this review, we summarize the present knowledge about the physiological and pathological roles of twin proteins, $\mathrm{CHCHD} 2$ and $\mathrm{CHCHD} 10$, in neurodegenerative diseases.
\end{abstract}

Keywords: coiled-coil-helix-coiled-coil-helix domain; OXPHOS; respiratory complexes; mitochondria; $\mathrm{CHCH}$ domain; MICOS; neurodegenerative diseases

\section{Introduction}

A mitochondrion is an essential organelle that converts nutrients into chemical energy by a oxidative phosphorylation (OXPHOS) reaction to provide ATP as energy in eukaryotic cells. Mitochondrion also plays multifaceted roles including cellular stress/immune response, metal ion metabolism, calcium signaling/buffering, apoptosis, and cytosolic protein degradation $[1,2]$. Mitochondria contain their own circular genome ( 16,600 base pairs), where only 37 genes (13 OXPHOSrelated proteins, 2 ribosomal RNAs and 22 tRNAs) are coded in eukaryotes [3]. Aside from the 13 OXPHOS proteins coded on the mitochondrial genome, approximately 1500 mitochondrial proteins coded in the nuclear genome are produced on the cytosolic ribosomes as precursor proteins and are imported into mitochondria via the mitochondrial import machinery [4].

Mitochondrial dysfunction is a hallmark of aging and a variety of disorders including ischemia/ reperfusion injury in stroke and myocardial infarction, metabolic syndromes, and neurodegeneration $[2,5]$. Mitochondrial dysfunction is often caused by acute or chronic oxidative stress derived from reactive oxygen species (ROS) during OXPHOS reaction. Cells are equipped with a variety of stress signaling to cope with this issue. However, the failure of OXPHOS components and dysfunction of signaling against oxidative stress would lead to chronic oxidative stress, which imperils the health of organisms. 
Mitochondrial proteins are generally small, which is attributed to the property of mitochondrial import machineries. Members of nucleus-encoded mitochondrial small proteins containing twin $\mathrm{CX}_{9} \mathrm{C}$ motifs $\left(\left(\mathrm{CX}_{9} \mathrm{C}\right)_{2}\right)$ are imported to the mitochondrial intermembrane space (IMS) and are folded by the disulfide relay-dependent Mia40 machinery [6]. The twin $\mathrm{CX}_{9} \mathrm{C}$ motifs form the coiled-coil-helix-coiled-coil-helix $(\mathrm{CHCH})$ domain, which is characterized by four cysteine residues, forming two disulfide bonds, stabilizing the helix-turn-helix fold (Figure 1).
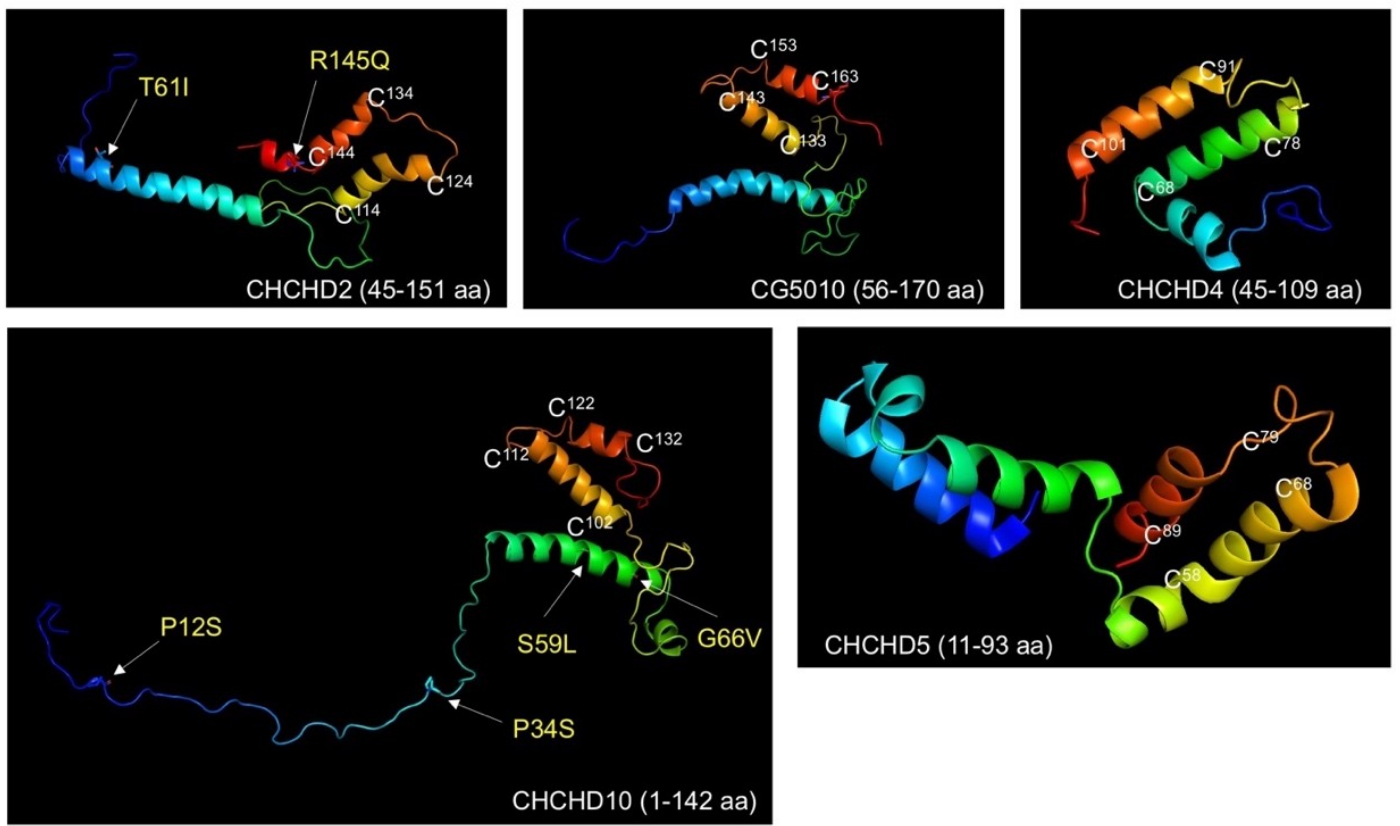

Figure 1. Structures of proteins containing twin $\mathrm{CX}_{9} \mathrm{C}$ motifs. The structures of human CHCHD4/Mia40 and human CHCHD5 were drawn from 2K3J and 2LQL deposited in the protein data bank. The predicted structures of human CHCHD2, human CHCHD10, and Drosophila CG5010 (an orthologue of $\mathrm{CHCHD} 2 / 10$ ) were depicted using RaptorX structure prediction server. The cold to warm colors indicate $\mathrm{N}$-terminal to $\mathrm{C}$-terminal region. The cysteine residues predicted to form disulfide bonds in twin $\mathrm{CX}_{9} \mathrm{C}$ motifs (white) and key residues associated with pathogenesis (yellow) are also shown. The central $\alpha$-helices (see also Figure 2) and twin $\mathrm{CX}_{9} \mathrm{C}$ motifs are highly conserved among CHCHD2, CHCHD10, and CG5010, while there are several predicted disorder regions in these proteins, which makes it difficult to draw accurate structures. Note that the predicted structures of CHCHD2, CHCHD10, and CG5010 may not reflect the physiological conformation due to in silico analysis.

Recently, mutations of the genes for mitochondrial twin $\mathrm{CX}_{9} \mathrm{C}$ proteins, $\mathrm{CHCHD} 2$ and $\mathrm{CHCHD10}$, were identified as being linked to the pathogenesis of Parkinson's diseases (PD) [7], amyotrophic lateral sclerosis (ALS) and frontotemporal lobe dementia (FTD) [8]. Subsequent studies have demonstrated that $\mathrm{CHCHD} 2$ and $\mathrm{CHCHD} 10$ are associated with a variety of dominantly inherited neurodegenerative diseases as well as sporadic neurodegenerative diseases [9]. In this review, we summarize the physiological functions of $\mathrm{CHCHD} 2$ and $\mathrm{CHCHD} 10$ and discuss their pathological roles in neurodegenerative disorders.

\section{Genetic and Pathological Overlaps between ALS and FTD, but not between ALS-FTD and PD}

ALS and FTD are clinically distinct adult-onset neurodegenerative diseases. ALS patients progressively exhibit muscle weakness, wasting and spasticity caused by degeneration of the motor neurons in the motor cortex, brainstem, and spinal cord, and eventually die from respiratory failure caused by the loss of the motor neurons innervating the respiratory muscles. In contrast, FTD patients display progressive disturbances to behavior, personality, language, cognitive functions, and motor function that are associated with degeneration of the neural network in the frontal and temporal lobes of the brain. In spite of the different clinical symptoms, 15\% of FTD cases also exhibit ALS phenotypes, 
whereas $15 \%$ of ALS cases have FTD with TAR DNA-binding protein 43 (TDP-43)-positive inclusions in the cortical neurons, and at least $50 \%$ of ALS cases show subtler cognitive and/or behavioral problems [10-12]. There are significant genetic overlaps between ALS and FTD, which is represented by C9orf72 expansions, mutations of TBK1, VCP, TDP-43, and CHCHD10. Thus, ALS and FTD are thought to represent a continuous disease spectrum. Although TDP-43 mutations are rare in ALS and FTD $(<1 \%)$, neuronal inclusions of TDP-43 in affected brain regions and motor neurons are reported in the majority of ALS (up to 97\%) and FTD (up to 50\%) cases [13-15].

$\mathrm{PD}$ is the most common neurodegenerative movement disorder, which is characterized by rigidity, tremor, and bradykinesia-phenotypes associated with the loss of dopaminergic neurons in the substantia nigra of the midbrain. Pathologically, $\alpha$-Synuclein-positive neuronal inclusions called Lewy bodies are found in the residual DA neurons. Although most PD cases are sporadic, $5-10 \%$ of patients carry monogenetic mutations. Over 20 genes or genetic loci for familial PD have been isolated, which includes SNCA/ $\alpha$-Synuclein, Parkin, PINK1, DJ-1, ATP13A2, DNAJC6, EIF4G1, FBXO7, LRRK2, VPS35, PLA2G6, SYNJ1, VPS13C, and CHCHD2 [16-18]. However, unlike in the case of ALS and FTD, there are minimal or no generic or pathological overlaps between PD and ALS-FTD [19].

\section{CHCHD2 Mutations Linked to PD}

CHCHD2 mutations have originally been identified with dominantly inherited PD [7]. Recent findings demonstrate that $\mathrm{CHCHD} 2$ mutations are associated with late-onset autosomal dominant PD, as well as sporadic PD and dementia with Lewy bodies (DLB). So far, two missense mutations (T61I and R145Q) and a splice-site mutation (c.300 + 5G > A) to induce non-sense-mediated mRNA decay have been identified as pathogenic variants linked to autosomal dominant PD. However, CHCHD2 mutations identified in PD patients in Asian populations appear to be absent in Caucasians. A recent study identified three novel putative pathogenic variants (A32T, P34L, and I80V) from four western European familial PD patients [20]. Representative pathogenic and risk variants are summarized in Figure 2.
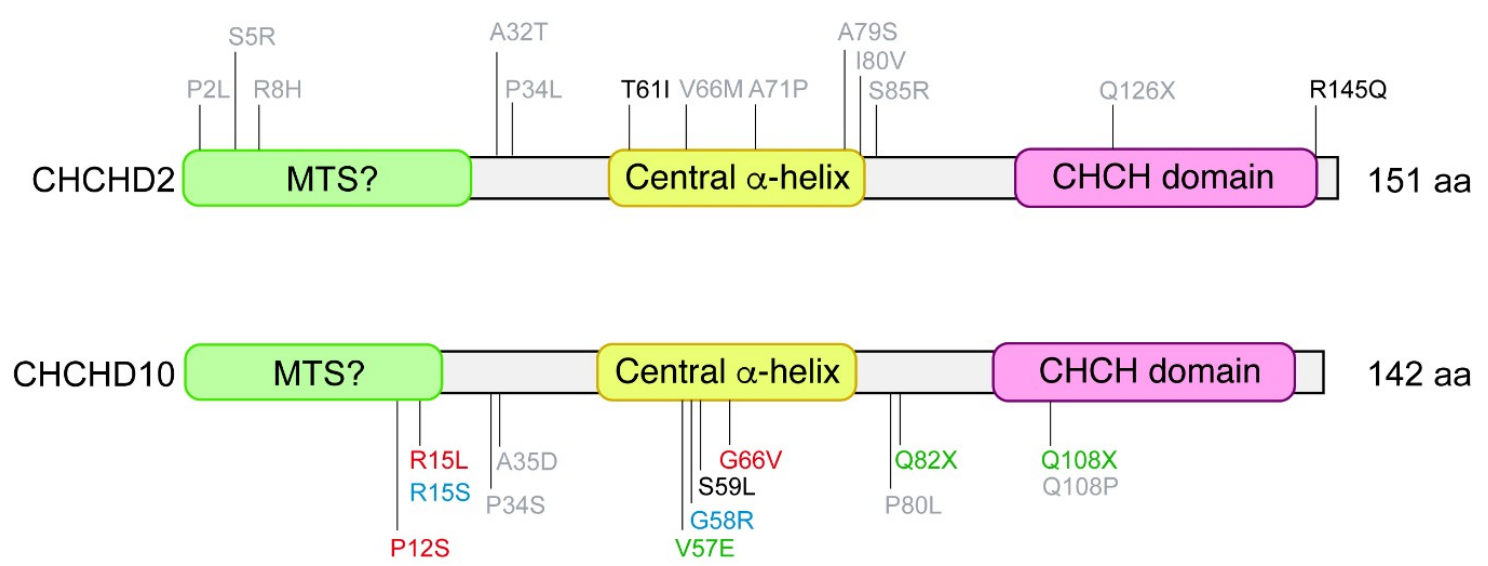

Figure 2. Representative disease-associated variants in the coding regions of CHCHD2 and CHCHD10. (Upper) Coding variants in PD patients are in black [7,30,31]. Potential risk variants found in PD [7,17, 30,32-37], DLB [32], AD [38,39], FTD [39], and MSA [40] patients without family history or sporadic cases are in gray. $\mathrm{CHCHD} 2 \mathrm{~T} 61 \mathrm{I}$ has been found in multiple families and has the greatest evidence for pathogenicity while R145Q has only been reported in the first case from familial PD population. Note that the pathogenicity of other variants is not fully determined due to the absence of segregation data in families and burden analysis of rare variants. (Lower) Coding variants in FTD patients $[23,25]$ are in green, in patients with ALS [21,23,24], CMT2 [26,27], or SMAJ [28] in red, in ALS-FTD patients [8,22] and patients with motor neuron disease [21] in black, and in mitochondrial myopathy patients [29] in blue. Potential risk variants found in ALS [41-45], FTD [44], FTD with PD pathology [25], AD [46], and ALS-FTD [22] patients are in grey. Note that R15S and G58R were found in cis and there is the possibility that one or the other but not both are pathogenic [29]. 


\section{CHCHD10 Mutations Linked to ALS-FTD}

The ALS-FTD-associated S59L mutation of CHCHD10 was first identified in a French family [8]. The patients were affected by motor neuron disease, frontotemporal dementia-like cognitive decline, cerebellar ataxia, and myopathy. Using a whole exome sequencing approach, the S59L mutation was shown to segregate with affected individuals. The same mutation was also identified in a patient of Spanish descent who presented signs of both ALS and FTD, in addition to having a family history of ALS. Therefore, $\mathrm{CHCHD10}$ has been recognized as a new ALS-FTD-causative gene. Subsequent studies have identified $\mathrm{CHCHD} 10$ mutations in European populations in association with a variety of phenotypes, mostly ALS and FTD [21-25], but also Charcot-Marie-Tooth disease type 2 (CMT2) [26,27], spinal motor neuronopathy [28], motor neuron disease [21], and mitochondrial myopathy patients [29]. Representative pathogenic and risk variants are summarized in Figure 2.

\section{Twin Proteins, CHCHD2, and CHCHD10 Regulate OXPHOS}

Human CHCHD2 and CHCHD10 proteins are very similar at amino acid sequence levels ( $54 \%$ identity by ClustalW alignment) (Figure 3). Both proteins are highly conserved from yeast to humans [47]. In yeast, loss of Mix17/Mic17 (orthologue of human CHCHD2 and CHCHD10) results in mild reduction of cytochrome $\mathrm{c}$ reductase (complex III) activity and increased cytochrome c oxidase (complex IV) activity while oxygen consumption is markedly suppressed [47]. However, complex III subunits (Cor2, Cyt1, and Rip1) and complex IV subunit (COX2) levels are not changed, suggesting that Mix17 regulates the enzymatic activities of complex III and complex IV [47]. In human cultured cells, the silencing of CHCHD2 reduces the cytochrome c oxidase activity, the oxygen consumption, and the expression of both mitochondrial DNA-encoded COX 2 and nucleus-encoded NDUFB8, a subunit of complex I [48], while the NADH:ubiquinone oxidoreductase (complex I) activity is not altered. An earlier study using transcriptional association analysis in human tissues reported that genes showing correlated expression with $\mathrm{CHCHD10}$ include the respiratory complex subunits [49]. Silencing of CHCHD10 in HeLa cells shows reduced ATP production and complex IV activity [49]. The observations of reduced oxygen consumption using yeast and human cells again suggest that the function of complex IV is mainly compromised by the suppression of CHCHD2 and $\mathrm{CHCHD10}$, affecting the activity of mitochondrial protein transport and of protein expression from the mitochondrial genome.
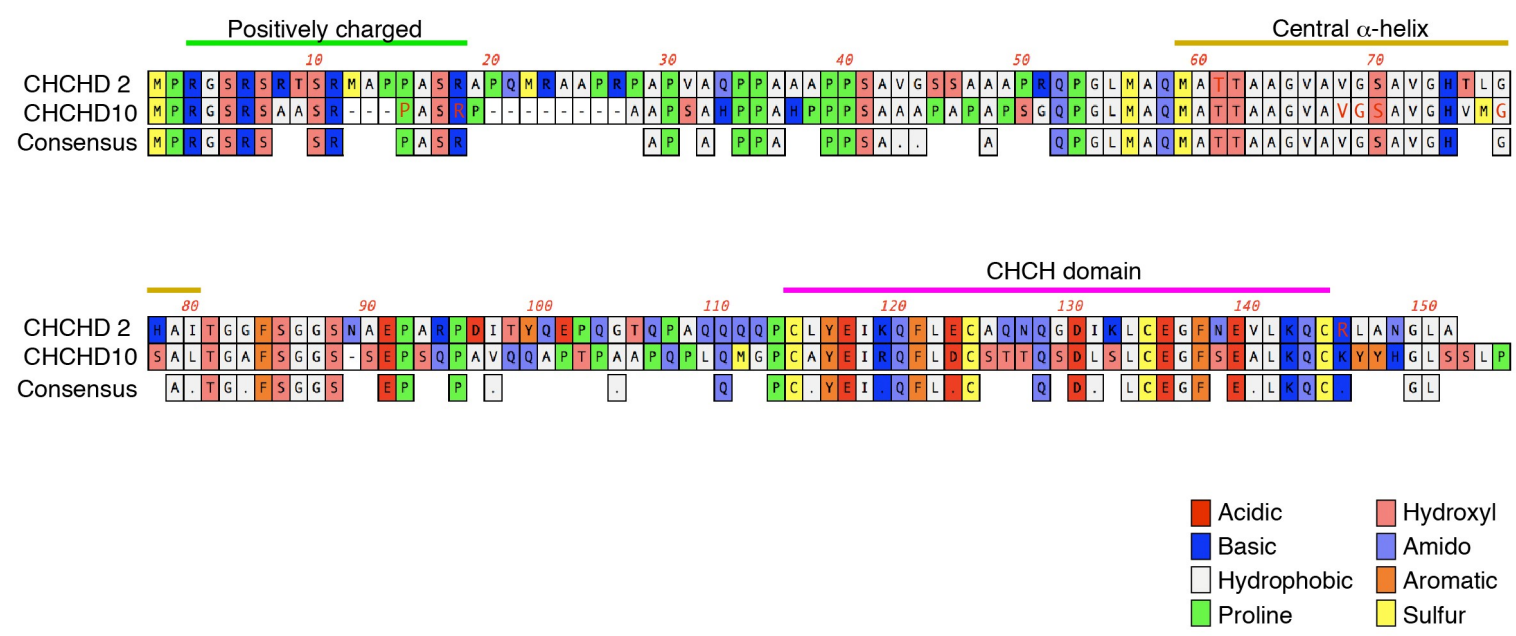

Figure 3. Alignment of human $\mathrm{CHCHD} 2$ and $\mathrm{CHCHD} 10$. N-terminal positively charged regions proposed as MTS, central $\alpha$-helices, and $\mathrm{CHCH}$ domains are shown. Sequence alignment was performed by ClustalW program while $\alpha$-helices and $\mathrm{CHCH}$ domains were predicted by the RaptorX program. Red letters in sequences indicate affected amino acids in neurodegenerative diseases. 
Drosophila has a single copy of the CHCHD2/CHCHD10 orthologue, CG5010. Loss of CG5010 results in reduced oxygen consumption, reduced ATP production, mitochondrial cristae dilation, higher ROS production, and apoptotic degeneration in muscles. These mitochondrial phenotypes are rescued by complemented expression of human wild-type CHCHD2, but not PD-associated T61I and R145Q mutants [50].

\section{Submitochondrial Localization of Twin Proteins}

A recent study indicated that CHCHD10 is imported to the IMS by Mia40 machinery through the $\mathrm{CHCH}$ domain of $\mathrm{CHCHD10}$, rather than the proposed MTS (1-16 aa) [45], while the requirement of both the MTS and $\mathrm{CHCH}$ domain is reported in other studies [51,52]. The requirement of the $\mathrm{CHCH}$ domain for mitochondrial import is also reported in $\mathrm{CHCHD} 3$, but $\mathrm{N}$-terminal myristoylation is another essential modification for its mitochondrial localization [53]. Although the four cysteines of the $\mathrm{CHCH}$ domain of $\mathrm{CHCHD} 3$ are important for binding to Mitofilin in the inner mitochondrial membrane, and the sorting and assembly machinery SAM50 for correct folding on the outer mitochondrial membrane, they are not essential for mitochondrial import.

CHCHD10 is enriched at the cristae junction in the IMS and maintains the cristae organization [8]. It is a proposed component of the mitochondrial contact site and cristae organizing system (MICOS) complex, which contains MIC60/Mitofilin, MIC27/APOOL, MIC25/CHCHD6, MIC19/CHCHD3, and MIC10/MINOS1, and maintains the cristae junction [54,55], although the finding that CHCHD10 is a MICOS subunit has failed to be supported by others [51,56,57]. The immunoelectron microscopic analysis suggests that $\mathrm{CHCHD} 2$ and $\mathrm{CHCHD} 10$ are not colocalized with $\mathrm{CHCHD} 3$, a component of the MICOS complex [57]. Consistent with the observations, we failed to detect the direct interaction between CHCHD2 and Mitofilin or CHCHD3 [57,58]. However, CHCHD2 and CHCHD10 could indirectly maintain MICOS integrity [58].

\section{Expressional Regulation and Tissue Expression of Twin Proteins}

A transcription factor, Nurr1, is essential for the development and survival of ventral midbrain dopaminergic neurons [59,60] and activates the expression of CHCHD2, along with several complex IV subunits and mitochondrial ribosomal proteins in dopaminergic neurons [61]. Reprograming-associated transcription factors, OCT4 and SOX2, recognize the CHCHD2 promoter, leading to transcriptional upregulation [62]. In this context, $\mathrm{CHCHD2}$ expression correlates with the differentiation potential to neuroectodermal lineages in human-induced pluripotent stem cells [62].

In coexpression network analysis using human B cells, CHCHD2 was predicted to be closely connected to transcription and glycolysis metabolism [63]. The roles of CHCHD2 in oxygen-dependent transactivation of mitochondrial proteins has also been proposed [64]. An isoform of cytochrome c oxidase subunit 4 (COX4I2), which is exclusively expressed in the lung, trachea, and placenta at high levels and in the heart and brain at low levels, contains a putative oxygen responsive element (ORE) in its promoter region of the nucleic genome. The ORE is also found in the promoter of CHCHD2. CHCHD2 binds to ORE and transcriptionally upregulates both COX4I2 and CHCHD2 itself in cooperation with Notch-associated transcription factor RBP-Jk/CSL/CBF1 under conditions of low oxygen, while wild-type CHCHD10, but not pathogenic variants, acts as a negative regulator of ORE-mediated translation $[64,65]$. Moreover, CHCHD2 along with CHCHD10 interacts with complex IV subunits, leading to increased oxygen consumption and reduced ROS production [66]. In the regulation of complex IV, the phosphorylation of CHCHD2 at Y99 by Abl2 kinase seems to be involved [67]. However, the direct interaction between complex IV and CHCHD2 failed to be detected in our study and Y99 residue is not conserved in lower organisms such as Drosophila and yeast [50]. For the roles of CHCHD10 in the nucleus, opposite results were reported in another study, where both wild-type CHCHD10 and ALS-FTD-associated mutants activated nucleus-encoded mitochondrial complex I genes, NADH dehydrogenase iron-sulfur protein 3 and NADH dehydrogenase-1 $\beta$ subcomplex 
subunit 6 [52]. Thus, further studies in terms of the roles of CHCHD2 and CHCHD10 in the nucleus would be warranted.

The expression pattern of CHCHD2 and CHCHD10 proteins appears to be similar at tissue levels and relatively high in the heart, liver, pancreas, and skeletal muscle while low in the forebrain and spinal cord in mice [51]. The immunohistochemical analysis has revealed that CHCHD2 and CHCHD10 immunosignals are rich in dopaminergic neurons of the substantia nigra, pyramidal neurons of the cortex and the hippocampus, and motor neurons in the anterior horn of the spinal cord. These are affected in PD, AD, and ALS-FTD [51,57]. Another study reported that the immunoreactivity of $\mathrm{CHCHD} 2$ is higher than that of $\mathrm{CHCHD} 10$ in dopaminergic neurons in the midbrain [58].

\section{Binding Partners of $\mathrm{CHCHD} 2$ and $\mathrm{CHCHD} 10$}

In human cultured cells, $\mathrm{CHCHD} 2$ has been suggested to be involved in apoptosis pathways through direct interaction with BCL-xL, an anti-apoptotic BCL-2-related protein, to prevent BAX oligomerization and subsequent cytochrome $c$ release from the IMS [68]. A CHCHD2-binding protein, MICS1, which was originally characterized as a cytochrome c-binding anti-apoptotic protein, suppressing the cytochrome c release, regulates cristae organization on the IMS in HeLa cells [69]. MICS1 overexpression suppresses the defects of cristae organization by loss of CG5010 in Drosophila, indicating that $\mathrm{CHCHD} 2$ in concert with MICS1 stabilizes cytochrome $\mathrm{c}$ in the respiratory complex, which would improve the electron transfer from complex III to complex IV (Figure 4) [50].
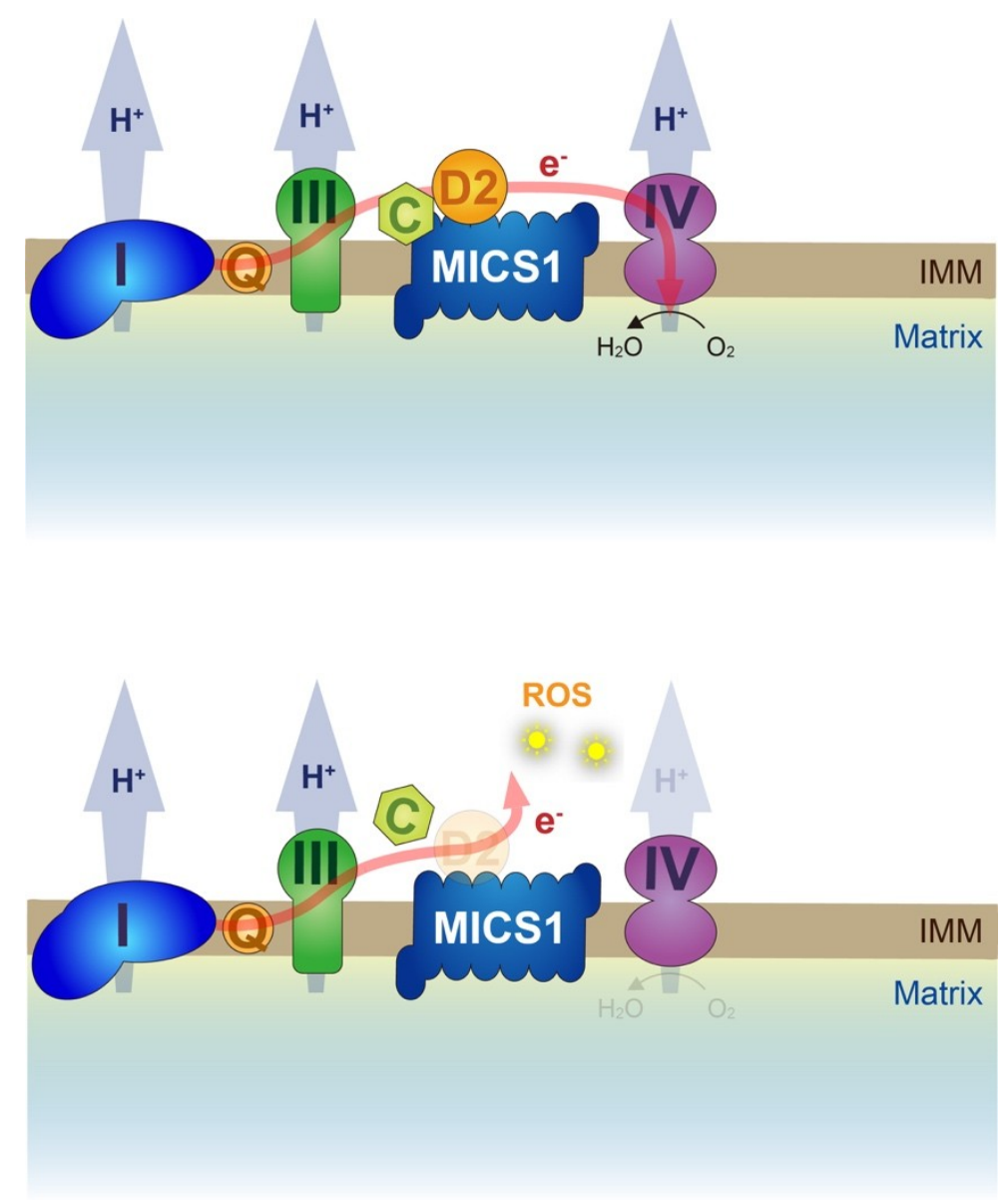

Figure 4. Working hypothesis for a role of CHCHD2 in the respiratory complex. (Upper) CHCHD2 (D2) along with MICS1 retains cytochrome c (c) in the respiratory complex, which stabilize electron flow from complex III to complex IV. (Lower) Loss of CHCHD2 destabilizes cytochrome c, leading to electron leak and subsequent ROS generation. IMM, inner mitochondrial membrane. 
CHCHD2 and CHCHD10 form both homodimer and heterodimer, although the physiological meanings remain unclear $[50,51,56,58]$. Some pathogenic mutations may affect the dimerization and/or mitochondrial localization, although the observations were different in each study. For instance, CHCHD10 R15L and S59L do not affect dimerization but may rather disturb normal mitochondrial localization [51] while CHCHD10 R15L is normally localized at the mitochondria, as shown in another study [56]. A thorough study using CHCHD2 and/or CHCHD10 knockout cultured cells revealed that $\mathrm{CHCHD} 2$ promotes $\mathrm{CHCH} 10$ oligomerization [57]. Endogenous $\mathrm{CHCHD} 10$ is present as a monomer in the absence of $\mathrm{CHCHD} 2$, while endogenous $\mathrm{CHCHD} 2$ forms a homodimer and promotes the formation of the $\mathrm{CHCHD} 2 / \mathrm{CHCHD} 10$ heterodimer. $\mathrm{CHCHD} 2$ is post-translationally stabilized upon the reduction of mitochondrial membrane potential $(\Delta \psi \mathrm{m})$ but not the changes in electron flux or ROS generation, facilitating CHCHD2/CHCHD10 heterodimer formation $[57,70,71]$. The regulation mechanism of their protein levels remains to be resolved, but the involvement of $\Delta \psi \mathrm{m}$-dependent mitochondrial proteases and/or the proteasome is expected [57,72]. In Drosophila, CG5010 also responds to mitochondrial DNA damage and mitochondrial unfolded protein stress, and is stabilized on the PD-associated PINK1, Parkin, or DJ-1-defefient genetic backgrounds [50]. Thus, CHCHD2 and $\mathrm{CHCHD} 10$ are suggested to have a role in relieving mitochondrial stress, in addition to the roles in OXPHOS regulation.

Both CHCHD2 and CHCHD10 also associate with a mitochondrial matrix protein p32/HABP1/ $\mathrm{C} 1 \mathrm{qBP} / \mathrm{gC} 1 \mathrm{qR}$, although the binding mode of IMS-resident CHCHD2 and CHCHD10 with p32 remains unclear [51,56,73]. The loss of $p 32$ causes developmental defects in mouse embryos with severe dysfunction of the mitochondrial respiratory chain due to impaired mitochondrial protein synthesis, suggesting that $\mathrm{p} 32$ is involved in mitochondrial translation mediated by mitoribosomes [74]. The role of p32 in neurotransmitter release at synapses was reported in Drosophila, suggesting that p32 regulates the $\mathrm{Ca}^{2+}$-buffering ability of mitochondria [75]. Although p32 is suggested to be involved in a variety of critical mitochondrial functions, our study using Drosophila failed to detect significant genetic interaction between $p 32$ and CG5010, in spite of the conserved physical association (Figure 5).
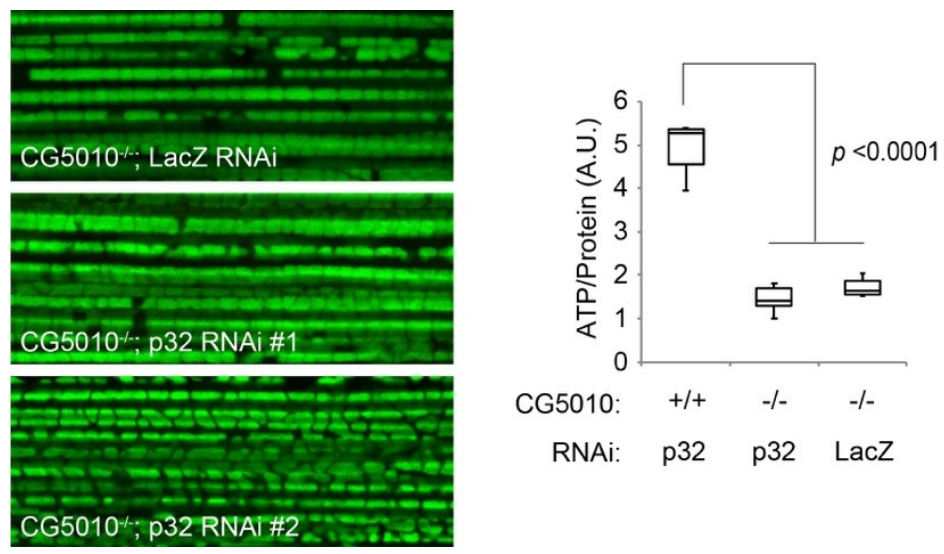

Figure 5. No evidence of genetic interaction between Drosophila CHCHD2/D10 orthologue, CG5010, and p32. (Left) Mitochondria in the indirect flight muscles were visualized by mitoGFP (green). Although p32-deficient flies are lethal, muscle-specific reduction of $p 32$ does not affect muscular mitochondria. Reduction of $p 32$ in CG5010 null flies does not change the mitochondrial morphology. Two independent p32 RNAi lines obtained from the NIG-fly were employed. LacZ RNAi served as mock control. (Right) Loss of CG5010 resulted in reduced ATP production $\left(p<0.0001\right.$, CG5010 ${ }^{+/+}$with $p 32$ RNAi vs. G5010-/- with $p 32$ RNAi by Tukey-Kramer's test), which was not affected by $p 32$ inactivation ( $p=0.5546$, G5010 $^{-/-}$with $p 32$ RNAi vs. G5010 ${ }^{-/}$with LacZ RNAi). $n=5-6$ in each group. A.U., arbitrary units. Transgenes were driven by muscle-specific MHC-GAL4 driver.

CHCHD2 and CHCHD10 appear to reside in a high molecular weight complex of approximately $220 \mathrm{kDa}$ [56]. In a glucose-free medium containing galactose, cells are forced to rely predominantly 
on OXPHOS rather than glycolysis for ATP production. Under this condition, CHCHD2 and $\mathrm{CHCHD} 10$ are upregulated and exist in a new complex of approximately $40 \mathrm{kDa}$, which indicates the rearrangement of $\mathrm{CHCHD2-}$ and $\mathrm{CHCHD} 10$-containing complexes in response to OXPHOS activity [56].

\section{Pathogenesis caused by Twin $\mathrm{CHCH}$ Proteins}

Mitochondrial defects have long been implicated in the etiology of PD as genetic evidence. Early-onset PD-causative genes, PINK1 and Parkin, are well recognized to regulate mitochondrial quality control, which includes the arrest of mitochondrial transport and removal of damaged mitochondria through mitophagy [76]. Interestingly, the immune response and autophagy-associated TBK1, Optineurin, VCP/p97, and SQSTM1/p62, which are causative genes of ALS-FTD, have been shown to be involved in PINK1-Parkin-mediated mitophagy [77-79]. Another early-onset PD-causative gene, $D J-1$, demonstrates resistance to oxidative stress [80,81].

Although CG5010 is upregulated in PINK1-, Parkin-, and DJ-1-deficient flies, probably due to chronic reduction of $\Delta \psi \mathrm{m}$, there was no evidence that CHCHD2/CHCHD10 and PINK1-Parkin signaling or DJ-1 directly interact [50]. Rather PINK1-Parkin activation exacerbated the CG5010 mitochondrial phenotypes, suggesting that PINK1-Parkin signaling tried to remove all of the defected mitochondria by CG5010 loss. A similar conclusion was reported by another study using human cultured cells [57].

TDP-43 is a heterogeneous ribonucleoprotein that plays a major role in regulating RNA splicing, stability, and transport. In ALS and FTD patients, the accumulation of TDP-43 in cell bodies of neurons in affected regions is often observed, indicating that a unifying pathology underlies the ALS-FTD spectrum. Mitochondrial mislocalization of TDP-43 and its involvement in neurotoxicity of ALS-FTD have also been reported [82]. Loss of CHCHD10 or ALS-FTD-associated CHCHD10 R15L and S59L mutants promotes cytosolic and mitochondrial localization of TDP-43 [52]. Another study comparing the effects of benign Jokela type spinal muscular atrophy (SMAJ)-linked CHCHD10 G66V and the more severe ALS-FTD-associated CHCHD10 S59L showed that the accumulation of phosphorylated TDP-43 is comparable among these mutants. Rather, MICOS assembly defects and mitochondrial fragmentation are well correlated with the severity of the disease [55]. Thus, the molecular relationship between CHCHD10 mutations and TDP-43 accumulation would need further study.

Although CHCHD2- and CHCHD10-linked neurodegenerative diseases are dominantly inherited, the findings of their mutations leading to premature protein truncation suggest mitochondrial phenotypes arise from haploinsufficiency. Supporting this idea, the expression of PD-associated human CHCHD2 mutants on a wild-type genetic background, but not CG5010 null background, does not produce obvious mitochondrial phenotypes in Drosophila [50]. However, another Drosophila study showed that the overexpression of human CHCHD2 mutants on a wild-type genetic background leads to mitochondrial degeneration and dopaminergic neuron loss. This may be attributed to higher levels of $\mathrm{CHCHD} 2$ ectopic expression and Myc-tag addition to CHCHD2, as even wild-type CHCHD2 expression caused a reduced electrophysiological response and shorter lifespan compared with a no transgene control. However, the finding that CHCHD2 T61I, which can form dimers with CHCHD2 [50] or CHCHD10 [58,83], tends to be insoluble suggests that at least CHCHD2 T61I has an aspect of toxic gain-of-function [50,57]. Similarly, a tendency of CHCHD10 S59L and G66V for insolubilization was shown [57]. Thus, the property of twin $\mathrm{CHCH}$ proteins to form homo- and heterodimer and the consequence of mutations in terms of solubility and dimer formation would produce a wide range of clinical and pathological manifestations (Figure 6). 


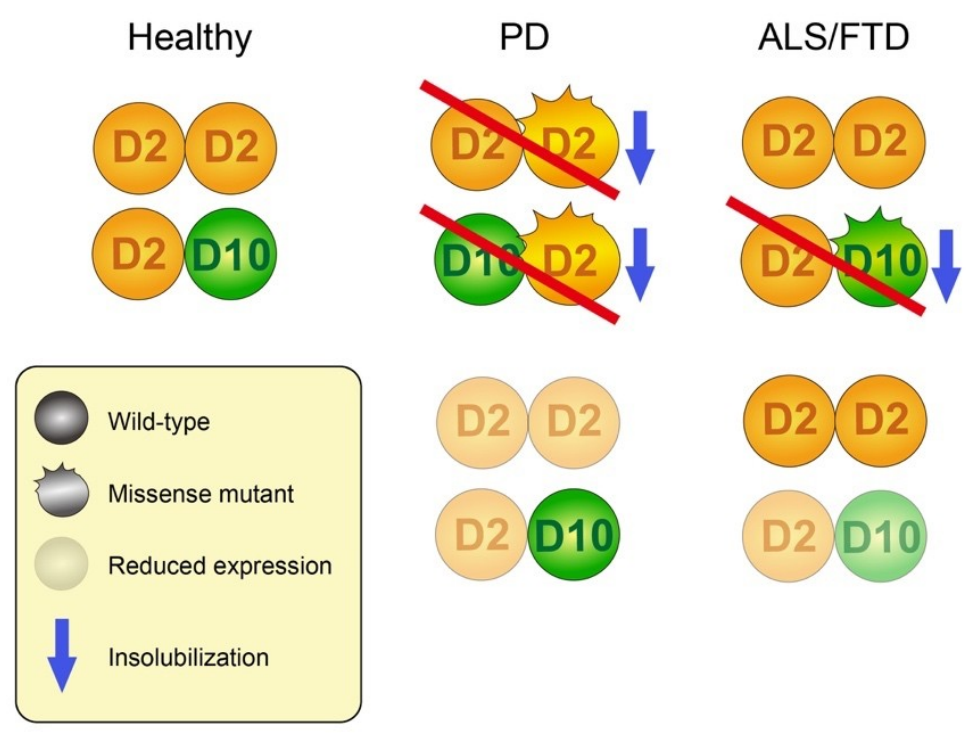

Figure 6. Working hypothesis showing that $\mathrm{CHCHD} 2$ and $\mathrm{CHCHD} 10$ produce a complicated disease spectrum. CHCHD2 forms a homodimer and stimulates heterodimerization with CHCHD10, which may be important to maintain mitochondrial activity [50,57]. In PD, CHCHD2 T61I mutation facilitates its insolubilization, which should involve the partners [50,57]. Splice-site mutation (c.300 + 5G > A) of $\mathrm{CHCHD} 2$ and variants in the untranslated region may reduce $\mathrm{CHCHD} 2$ expression [7,32]. In both cases, functional CHCHD2 is reduced. In ALS-FTD, CHCHD10 G59L and G66V mutations facilitate their insolubilization, which should involve wild-type CHCHD2 [57]. Variants in the untranslated region of $\mathrm{CHCHD10}$ or truncated $\mathrm{CHCHD} 10$ mutants that cannot bind to CHCHD2 may also cause pathogenesis due to haploinsufficiency, although there are no experimental data so far. In both cases, the CHCHD2 homodimer will be intact.

\section{Conclusions and Perspective}

Although the mutation frequency of $\mathrm{CHCHD} 2$ and $\mathrm{CHCHD} 10$ is relatively low, the fact that many pathogenic and risk variants of the two genes have been isolated from patients with a variety of neurodegenerative diseases strongly suggests that the dysfunctions of these twin proteins underlie the pathogenesis of major neurodegenerative diseases. Considering the observations that CHCHD2 and CHCHD10 form different patterns of mutant complex, there could be multiple modes of pathogenesis in these diseases. In addition, not a few mutations of both genes are found in sporadic neurodegenerative diseases, raising the possibility that the two genes are key factors in polygenic hereditary diseases. Thus, it would be important to examine both gene mutations simultaneously. Finally, what mechanism by the dysfunctions of the twin proteins determines the affected nervous system? The issue is the "twin paradox" in current neurology.

Author Contributions: Writing—original draft preparation, Y.I., and H.M.; investigation, H.M., and K.S.-F.; writing-review and editing, Y.I.; supervision, N.H.; funding acquisition, Y.I., H.M., and N.H.

Funding: This study was supported by a Grant-in-Aid for Scientific Research (17H04049 to Y.I., 16K19525 to H.M., and 18H04043 to N.H.) from JSPS in Japan and was partially supported by a grant from Otsuka Pharmaceutical (Y.I. and N.H.).

Acknowledgments: We thank F. Kawasaki for providing Drosophila p32-related materials, and T. Inoshita, Y. Aoki, and C. Amano for their technical assistance.

Conflicts of Interest: The authors declare no conflict of interest. The founders had no role in the design of the study; in the collection, analyses, or interpretation of data; in the writing of the manuscript, or in the decision to publish the results. 


\section{Abbreviations}

$\begin{array}{ll}\text { AD } & \text { Alzheimer's disease } \\ \text { ALS } & \text { Amyotrophic lateral sclerosis } \\ \text { CHCH } & \text { Coiled-coil-helix-coiled-coil-helix } \\ \text { CMT2 } & \text { Charcot-Marie-Tooth disease type } 2 \\ \text { COX } & \text { Cytochrome c oxidase } \\ \text { DLB } & \text { Dementia with Lewy bodies } \\ \text { FTD } & \text { Frontotemporal lobe dementia } \\ \text { IMS } & \text { Mitochondrial intermembrane space } \\ \text { Mia40 } & \text { Mitochondrial intermembrane space import and assembly protein } 40 \mathrm{kDa} \\ \text { MTS } & \text { Mitochondrial targeting sequence } \\ \text { MICOS } & \text { Mitochondrial contact site complex } \\ \text { OXPHOS } & \text { Oxidative phosphorylation } \\ \text { PD } & \text { Parkinson's disease } \\ \text { ROS } & \text { Redox oxygen species } \\ \text { SMAJ } & \text { Jokela type spinal muscular atrophy } \\ \text { TDP-43 } & \text { TAR DNA binding protein of } 43 \mathrm{kDa} \\ \Delta \psi m & \text { Mitochondrial membrane potential }\end{array}$

\section{References}

1. Gorman, G.S.; Chinnery, P.F.; DiMauro, S.; Hirano, M.; Koga, Y.; McFarland, R.; Suomalainen, A.; Thorburn, D.R.; Zeviani, M.; Turnbull, D.M. Mitochondrial diseases. Nat. Rev. Dis. Primers 2016, 2, 16080. [CrossRef]

2. Suomalainen, A.; Battersby, B.J. Mitochondrial diseases: The contribution of organelle stress responses to pathology. Nat. Rev. Mol. Cell Biol. 2018, 19, 77-92. [CrossRef]

3. Mishra, P.; Chan, D.C. Mitochondrial dynamics and inheritance during cell division, development and disease. Nat. Rev. Mol. Cell Biol. 2014, 15, 634-646. [CrossRef]

4. Harbauer, A.B.; Zahedi, R.P.; Sickmann, A.; Pfanner, N.; Meisinger, C. The protein import machinery of mitochondria-a regulatory hub in metabolism, stress, and disease. Cell Metab. 2014, 19, 357-372. [CrossRef]

5. Rahman, J.; Rahman, S. Mitochondrial medicine in the omics era. Lancet 2018, 391, 2560-2574. [CrossRef]

6. Fischer, M.; Horn, S.; Belkacemi, A.; Kojer, K.; Petrungaro, C.; Habich, M.; Ali, M.; Kuttner, V.; Bien, M.; Kauff, F.; et al. Protein import and oxidative folding in the mitochondrial intermembrane space of intact mammalian cells. Mol. Biol. Cell 2013, 24, 2160-2170. [CrossRef]

7. Funayama, M.; Ohe, K.; Amo, T.; Furuya, N.; Yamaguchi, J.; Saiki, S.; Li, Y.; Ogaki, K.; Ando, M.; Yoshino, H.; et al. CHCHD2 mutations in autosomal dominant late-onset Parkinson's disease: A genome-wide linkage and sequencing study. Lancet. Neurol. 2015, 14, 274-282. [CrossRef]

8. Bannwarth, S.; Ait-El-Mkadem, S.; Chaussenot, A.; Genin, E.C.; Lacas-Gervais, S.; Fragaki, K.; Berg-Alonso, L.; Kageyama, Y.; Serre, V.; Moore, D.G.; et al. A mitochondrial origin for frontotemporal dementia and amyotrophic lateral sclerosis through CHCHD10 involvement. Brain 2014, 137, 2329-2345. [CrossRef]

9. Klemann, C.; Martens, G.J.M.; Sharma, M.; Martens, M.B.; Isacson, O.; Gasser, T.; Visser, J.E.; Poelmans, G. Integrated molecular landscape of Parkinson's disease. NPJ Parkinsons Dis. 2017, 3, 14. [CrossRef]

10. Ringholz, G.M.; Appel, S.H.; Bradshaw, M.; Cooke, N.A.; Mosnik, D.M.; Schulz, P.E. Prevalence and patterns of cognitive impairment in sporadic ALS. Neurology 2005, 65, 586-590. [CrossRef]

11. Lomen-Hoerth, C. Clinical phenomenology and neuroimaging correlates in ALS-FTD. J. Mol. Neurosci. 2011, 45, 656-662. [CrossRef]

12. Robberecht, W.; Philips, T. The changing scene of amyotrophic lateral sclerosis. Nat. Rev. Neurosci. 2013, 14, 248-264. [CrossRef]

13. Ling, S.C.; Polymenidou, M.; Cleveland, D.W. Converging mechanisms in ALS and FTD: Disrupted RNA and protein homeostasis. Neuron 2013, 79, 416-438. [CrossRef]

14. Mackenzie, I.R.A.; Neumann, M. Molecular neuropathology of frontotemporal dementia: Insights into disease mechanisms from postmortem studies. J. Neurochem. 2016, 138, 54-70. [CrossRef] 
15. Nguyen, H.P.; Van Broeckhoven, C.; van der Zee, J. ALS Genes in the Genomic Era and their Implications for FTD. Trends Genet. 2018, 34, 404-423. [CrossRef]

16. Puschmann, A. New Genes Causing Hereditary Parkinson's Disease or Parkinsonism. Curr. Neurol. Neurosci. Rep. 2017, 17, 66. [CrossRef]

17. Yang, N.; Zhao, Y.; Liu, Z.; Zhang, R.; He, Y.; Zhou, Y.; Xu, Q.; Sun, Q.; Yan, X.; Guo, J.; et al. Systematically analyzing rare variants of autosomal-dominant genes for sporadic Parkinson's disease in a Chinese cohort. Neurobiol. Aging 2018. Available online 20 November 2018. [CrossRef]

18. Inoshita, T.; Cui, C.; Hattori, N.; Imai, Y. Regulation of membrane dynamics by Parkinson's disease-associated genes. J. Genet. 2018, 97, 715-725. [CrossRef]

19. Karch, C.M.; Wen, N.; Fan, C.C.; Yokoyama, J.S.; Kouri, N.; Ross, O.A.; Hoglinger, G.; Muller, U.; Ferrari, R.; Hardy, J.; et al. Selective Genetic Overlap Between Amyotrophic Lateral Sclerosis and Diseases of the Frontotemporal Dementia Spectrum. JAMA Neurol. 2018, 75, 860-875. [CrossRef]

20. Jansen, I.E.; Bras, J.M.; Lesage, S.; Schulte, C.; Gibbs, J.R.; Nalls, M.A.; Brice, A.; Wood, N.W.; Morris, H.; Hardy, J.A.; et al. CHCHD2 and Parkinson's disease. Lancet Neurol. 2015, 14, 678-679. [CrossRef]

21. Muller, K.; Andersen, P.M.; Hubers, A.; Marroquin, N.; Volk, A.E.; Danzer, K.M.; Meitinger, T.; Ludolph, A.C.; Strom, T.M.; Weishaupt, J.H. Two novel mutations in conserved codons indicate that CHCHD10 is a gene associated with motor neuron disease. Brain 2014, 137, e309. [CrossRef]

22. Chaussenot, A.; Le Ber, I.; Ait-El-Mkadem, S.; Camuzat, A.; de Septenville, A.; Bannwarth, S.; Genin, E.C.; Serre, V.; Auge, G.; French research network on, F.T.D.; et al. Screening of CHCHD10 in a French cohort confirms the involvement of this gene in frontotemporal dementia with amyotrophic lateral sclerosis patients. Neurobiol. Aging 2014, 35, 2884 e2881-2884 e2884. [CrossRef]

23. Dols-Icardo, O.; Nebot, I.; Gorostidi, A.; Ortega-Cubero, S.; Hernandez, I.; Rojas-Garcia, R.; Garcia-Redondo, A.; Povedano, M.; Llado, A.; Alvarez, V.; et al. Analysis of the CHCHD10 gene in patients with frontotemporal dementia and amyotrophic lateral sclerosis from Spain. Brain 2015, 138, e400. [CrossRef]

24. Kurzwelly, D.; Kruger, S.; Biskup, S.; Heneka, M.T. A distinct clinical phenotype in a German kindred with motor neuron disease carrying a CHCHD10 mutation. Brain 2015, 138, e376. [CrossRef]

25. Perrone, F.; Nguyen, H.P.; Van Mossevelde, S.; Moisse, M.; Sieben, A.; Santens, P.; De Bleecker, J.; Vandenbulcke, M.; Engelborghs, S.; Baets, J.; et al. Investigating the role of ALS genes CHCHD10 and TUBA4A in Belgian FTD-ALS spectrum patients. Neurobiol. Aging 2017, 51, 177.e9-177.e16. [CrossRef]

26. Auranen, M.; Ylikallio, E.; Shcherbii, M.; Paetau, A.; Kiuru-Enari, S.; Toppila, J.P.; Tyynismaa, H. CHCHD10 variant p.(Gly66Val) causes axonal Charcot-Marie-Tooth disease. Neurol. Genet. 2015, 1, e1. [CrossRef]

27. Pasanen, P.; Myllykangas, L.; Poyhonen, M.; Kiuru-Enari, S.; Tienari, P.J.; Laaksovirta, H.; Toppila, J.; Ylikallio, E.; Tyynismaa, H.; Auranen, M. Intrafamilial clinical variability in individuals carrying the CHCHD10 mutation Gly66Val. Acta Neurol. Scand. 2016, 133, 361-366. [CrossRef]

28. Penttila, S.; Jokela, M.; Saukkonen, A.M.; Toivanen, J.; Palmio, J.; Lahdesmaki, J.; Sandell, S.; Shcherbii, M.; Auranen, M.; Ylikallio, E.; et al. CHCHD10 mutations and motor neuron disease: The distribution in Finnish patients. J. Neurol. Neurosurg. Psychiatry 2017, 88, 272-277. [CrossRef]

29. Ajroud-Driss, S.; Fecto, F.; Ajroud, K.; Lalani, I.; Calvo, S.E.; Mootha, V.K.; Deng, H.X.; Siddique, N.; Tahmoush, A.J.; Heiman-Patterson, T.D.; et al. Mutation in the novel nuclear-encoded mitochondrial protein CHCHD10 in a family with autosomal dominant mitochondrial myopathy. Neurogenetics 2015, 16, 1-9. [CrossRef]

30. Shi, C.H.; Mao, C.Y.; Zhang, S.Y.; Yang, J.; Song, B.; Wu, P.; Zuo, C.T.; Liu, Y.T.; Ji, Y.; Yang, Z.H.; et al. CHCHD2 gene mutations in familial and sporadic Parkinson's disease. Neurobiol. Aging 2016, 38, 217.e9-217.e13. [CrossRef]

31. Mao, C.Y.; Wu, P.; Zhang, S.Y.; Yang, J.; Liu, Y.T.; Zuo, C.T.; Zhuang, Z.P.; Shi, C.H.; Xu, Y.M. Brain glucose metabolism changes in Parkinson's disease patients with CHCHD2 mutation based on F-18-FDG PET imaging. J. Neurol. Sci. 2016, 369, 303-305. [CrossRef]

32. Ogaki, K.; Koga, S.; Heckman, M.G.; Fiesel, F.C.; Ando, M.; Labbe, C.; Lorenzo-Betancor, O.; Moussaud-Lamodiere, E.L.; Soto-Ortolaza, A.I.; Walton, R.L.; et al. Mitochondrial targeting sequence variants of the CHCHD2 gene are a risk for Lewy body disorders. Neurology 2015, 85, 2016-2025. [CrossRef]

33. Puschmann, A.; Dickson, D.W.; Englund, E.; Wszolek, Z.K.; Ross, O.A. CHCHD2 and Parkinson's disease. Lancet. Neurol. 2015, 14, 679. [CrossRef] 
34. Koschmidder, E.; Weissbach, A.; Bruggemann, N.; Kasten, M.; Klein, C.; Lohmann, K. A nonsense mutation in CHCHD2 in a patient with Parkinson disease. Neurology 2016, 86, 577-579. [CrossRef]

35. Yang, X.; Zhao, Q.; An, R.; Zheng, J.; Tian, S.; Chen, Y.; Xu, Y. Mutational scanning of the CHCHD2 gene in Han Chinese patients with Parkinson's disease and meta-analysis of the literature. Parkinsonism Relat. Disord. 2016, 29, 42-46. [CrossRef]

36. Ikeda, A.; Matsushima, T.; Daida, K.; Nakajima, S.; Conedera, S.; Li, Y.; Yoshino, H.; Oyama, G.; Funayama, M.; Nishioka, K.; et al. A novel mutation of CHCHD2 p.R8H in a sporadic case of Parkinson's disease. Parkinsonism Relat. Disord. 2017, 34, 66-68. [CrossRef]

37. Lee, R.G.; Sedghi, M.; Salari, M.; Shearwood, A.J.; Stentenbach, M.; Kariminejad, A.; Goullee, H.; Rackham, O.; Laing, N.G.; Tajsharghi, H.; et al. Early-onset Parkinson disease caused by a mutation in CHCHD2 and mitochondrial dysfunction. Neurol. Genet. 2018, 4, e276. [CrossRef]

38. Liu, X.; Jiao, B.; Zhang, W.; Xiao, T.; Hou, L.; Pan, C.; Tang, B.; Shen, L. Identification of CHCHD2 mutations in patients with Alzheimer's disease, amyotrophic lateral sclerosis and frontotemporal dementia in China. Mol. Med. Rep. 2018, 18, 461-466. [CrossRef]

39. Che, X.Q.; Zhao, Q.H.; Huang, Y.; Li, X.; Ren, R.J.; Chen, S.D.; Guo, Q.H.; Wang, G. Mutation Screening of the CHCHD2 Gene for Alzheimer's Disease and Frontotemporal Dementia in Chinese Mainland Population. J. Alzheimers Dis. 2018, 61, 1283-1288. [CrossRef]

40. Nicoletti, G.; Gagliardi, M.; Procopio, R.; Iannello, G.; Morelli, M.; Annesi, G.; Quattrone, A. A new CHCHD2 mutation identified in a southern italy patient with multiple system atrophy. Parkinsonism Relat. Disord. 2018, 47, 91-93. [CrossRef]

41. Johnson, J.O.; Glynn, S.M.; Gibbs, J.R.; Nalls, M.A.; Sabatelli, M.; Restagno, G.; Drory, V.E.; Chio, A.; Rogaeva, E.; Traynor, B.J. Mutations in the CHCHD10 gene are a common cause of familial amyotrophic lateral sclerosis. Brain 2014, 137, e311. [CrossRef]

42. Ronchi, D.; Riboldi, G.; Del Bo, R.; Ticozzi, N.; Scarlato, M.; Galimberti, D.; Corti, S.; Silani, V.; Bresolin, N.; Comi, G.P. CHCHD10 mutations in Italian patients with sporadic amyotrophic lateral sclerosis. Brain 2015, 138, e372. [CrossRef]

43. Chio, A.; Mora, G.; Sabatelli, M.; Caponnetto, C.; Traynor, B.J.; Johnson, J.O.; Nalls, M.A.; Calvo, A.; Moglia, C.; Borghero, G.; et al. CHCH10 mutations in an Italian cohort of familial and sporadic amyotrophic lateral sclerosis patients. Neurobiol. Aging 2015, 36, 1767 e1763-1767 e1766. [CrossRef]

44. Zhang, M.; Xi, Z.; Zinman, L.; Bruni, A.C.; Maletta, R.G.; Curcio, S.A.; Rainero, I.; Rubino, E.; Pinessi, L.; Nacmias, B.; et al. Mutation analysis of CHCHD10 in different neurodegenerative diseases. Brain 2015, 138, e380. [CrossRef]

45. Lehmer, C.; Schludi, M.H.; Ransom, L.; Greiling, J.; Junghanel, M.; Exner, N.; Riemenschneider, H.; van der Zee, J.; Van Broeckhoven, C.; Weydt, P.; et al. A novel CHCHD10 mutation implicates a Mia40-dependent mitochondrial import deficit in ALS. EMBO Mol. Med. 2018, 10, e8558. [CrossRef]

46. Xiao, T.; Jiao, B.; Zhang, W.; Pan, C.; Wei, J.; Liu, X.; Zhou, Y.; Zhou, L.; Tang, B.; Shen, L. Identification of CHCHD10 Mutation in Chinese Patients with Alzheimer Disease. Mol. Neurobiol. 2017, 54, 5243-5247. [CrossRef]

47. Longen, S.; Bien, M.; Bihlmaier, K.; Kloeppel, C.; Kauff, F.; Hammermeister, M.; Westermann, B.; Herrmann, J.M.; Riemer, J. Systematic analysis of the twin cx(9)c protein family. J. Mol. Biol. 2009, 393, 356-368. [CrossRef]

48. Baughman, J.M.; Nilsson, R.; Gohil, V.M.; Arlow, D.H.; Gauhar, Z.; Mootha, V.K. A computational screen for regulators of oxidative phosphorylation implicates SLIRP in mitochondrial RNA homeostasis. PLoS Genet. 2009, 5, e1000590. [CrossRef]

49. Martherus, R.S.; Sluiter, W.; Timmer, E.D.; VanHerle, S.J.; Smeets, H.J.; Ayoubi, T.A. Functional annotation of heart enriched mitochondrial genes GBAS and CHCHD10 through guilt by association. Biochem. Biophys. Res. Commun. 2010, 402, 203-208. [CrossRef]

50. Meng, H.; Yamashita, C.; Shiba-Fukushima, K.; Inoshita, T.; Funayama, M.; Sato, S.; Hatta, T.; Natsume, T.; Umitsu, M.; Takagi, J.; et al. Loss of Parkinson's disease-associated protein CHCHD2 affects mitochondrial crista structure and destabilizes cytochrome c. Nat. Commun. 2017, 8, 15500. [CrossRef]

51. Burstein, S.R.; Valsecchi, F.; Kawamata, H.; Bourens, M.; Zeng, R.; Zuberi, A.; Milner, T.A.; Cloonan, S.M.; Lutz, C.; Barrientos, A.; et al. In vitro and in vivo studies of the ALS-FTLD protein CHCHD10 reveal novel mitochondrial topology and protein interactions. Human Mol. Genet. 2018, 27, 160-177. [CrossRef] [PubMed] 
52. Woo, J.A.; Liu, T.; Trotter, C.; Fang, C.C.; De Narvaez, E.; LePochat, P.; Maslar, D.; Bukhari, A.; Zhao, X.; Deonarine, A.; et al. Loss of function CHCHD10 mutations in cytoplasmic TDP-43 accumulation and synaptic integrity. Nat. Commun. 2017, 8, 15558. [CrossRef] [PubMed]

53. Darshi, M.; Trinh, K.N.; Murphy, A.N.; Taylor, S.S. Targeting and import mechanism of coiled-coil helix coiled-coil helix domain-containing protein 3 (ChChd3) into the mitochondrial intermembrane space. J. Biol. Chem. 2012, 287, 39480-39491. [CrossRef] [PubMed]

54. Genin, E.C.; Plutino, M.; Bannwarth, S.; Villa, E.; Cisneros-Barroso, E.; Roy, M.; Ortega-Vila, B.; Fragaki, K.; Lespinasse, F.; Pinero-Martos, E.; et al. CHCHD10 mutations promote loss of mitochondrial cristae junctions with impaired mitochondrial genome maintenance and inhibition of apoptosis. EMBO Mol. Med. 2016, 8, 58-72. [CrossRef] [PubMed]

55. Genin, E.C.; Bannwarth, S.; Lespinasse, F.; Ortega-Vila, B.; Fragaki, K.; Itoh, K.; Villa, E.; Lacas-Gervais, S.; Jokela, M.; Auranen, M.; et al. Loss of MICOS complex integrity and mitochondrial damage, but not TDP-43 mitochondrial localisation, are likely associated with severity of CHCHD10-related diseases. Neurobiol. Dis. 2018, 119, 159-171. [CrossRef] [PubMed]

56. Straub, I.R.; Janer, A.; Weraarpachai, W.; Zinman, L.; Robertson, J.; Rogaeva, E.; Shoubridge, E.A. Loss of $\mathrm{CHCHD} 10-\mathrm{CHCHD} 2$ complexes required for respiration underlies the pathogenicity of a CHCHD10 mutation in ALS. Human Mol. Genet. 2018, 27, 178-189. [CrossRef] [PubMed]

57. Huang, X.; Wu, B.P.; Nguyen, D.; Liu, Y.T.; Marani, M.; Hench, J.; Benit, P.; Kozjak-Pavlovic, V.; Rustin, P.; Frank, S.; et al. CHCHD2 accumulates in distressed mitochondria and facilitates oligomerization of CHCHD10. Human Mol. Genet. 2018, 27, 3881-3900. [CrossRef]

58. Zhou, W.; Ma, D.; Sun, A.X.; Tran, H.D.; Ma, D.L.; Singh, B.K.; Zhou, J.; Zhang, J.; Wang, D.; Zhao, Y.; et al. PD-linked CHCHD2 mutations impair CHCHD10 and MICOS complex leading to mitochondria dysfunction. Human Mol. Genet.. in press. [CrossRef]

59. Zetterstrom, R.H.; Solomin, L.; Jansson, L.; Hoffer, B.J.; Olson, L.; Perlmann, T. Dopamine neuron agenesis in Nurr1-deficient mice. Science 1997, 276, 248-250. [CrossRef]

60. Kadkhodaei, B.; Ito, T.; Joodmardi, E.; Mattsson, B.; Rouillard, C.; Carta, M.; Muramatsu, S.; Sumi-Ichinose, C.; Nomura, T.; Metzger, D.; et al. Nurr1 is required for maintenance of maturing and adult midbrain dopamine neurons. J. Neurosci. 2009, 29, 15923-15932. [CrossRef]

61. Kadkhodaei, B.; Alvarsson, A.; Schintu, N.; Ramskold, D.; Volakakis, N.; Joodmardi, E.; Yoshitake, T.; Kehr, J.; Decressac, M.; Bjorklund, A.; et al. Transcription factor Nurr1 maintains fiber integrity and nuclear-encoded mitochondrial gene expression in dopamine neurons. Proc. Natl. Acad. Sci. USA 2013, 110, 2360-2365. [CrossRef] [PubMed]

62. Zhu, L.; Gomez-Duran, A.; Saretzki, G.; Jin, S.; Tilgner, K.; Melguizo-Sanchis, D.; Anyfantis, G.; Al-Aama, J.; Vallier, L.; Chinnery, P.; et al. The mitochondrial protein CHCHD2 primes the differentiation potential of human induced pluripotent stem cells to neuroectodermal lineages. J. Cell Biol. 2016, 215, 187-202. [CrossRef]

63. Nayak, R.R.; Kearns, M.; Spielman, R.S.; Cheung, V.G. Coexpression network based on natural variation in human gene expression reveals gene interactions and functions. Genome Res. 2009, 19, 1953-1962. [CrossRef] [PubMed]

64. Aras, S.; Pak, O.; Sommer, N.; Finley, R., Jr.; Huttemann, M.; Weissmann, N.; Grossman, L.I. Oxygendependent expression of cytochrome c oxidase subunit 4-2 gene expression is mediated by transcription factors RBPJ, CXXC5 and CHCHD2. Nucleic Acids Res. 2013, 41, 2255-2266. [CrossRef] [PubMed]

65. Aras, S.; Bai, M.; Lee, I.; Springett, R.; Huttemann, M.; Grossman, L.I. MNRR1 (formerly CHCHD2) is a bi-organellar regulator of mitochondrial metabolism. Mitochondrion 2015, 20, 43-51. [CrossRef] [PubMed]

66. Purandare, N.; Somayajulu, M.; Huttemann, M.; Grossman, L.I.; Aras, S. The cellular stress proteins CHCHD10 and MNRR1 (CHCHD2): Partners in mitochondrial and nuclear function and dysfunction. J. Biol. Chem. 2018, 293, 6517-6529. [CrossRef] [PubMed]

67. Aras, S.; Arrabi, H.; Purandare, N.; Huttemann, M.; Kamholz, J.; Zuchner, S.; Grossman, L.I. Abl2 kinase phosphorylates Bi-organellar regulator MNRR1 in mitochondria, stimulating respiration. Biochim. Biophys. Acta Mol. Cell Res. 2017, 1864, 440-448. [CrossRef]

68. Liu, Y.; Clegg, H.V.; Leslie, P.L.; Di, J.; Tollini, L.A.; He, Y.; Kim, T.H.; Jin, A.; Graves, L.M.; Zheng, J.; et al. CHCHD2 inhibits apoptosis by interacting with Bcl-x L to regulate Bax activation. Cell Death Differ. 2015, 22, 1035-1046. [CrossRef] 
69. Oka, T.; Sayano, T.; Tamai, S.; Yokota, S.; Kato, H.; Fujii, G.; Mihara, K. Identification of a novel protein MICS1 that is involved in maintenance of mitochondrial morphology and apoptotic release of cytochrome c. Mol. Biol. Cell 2008, 19, 2597-2608. [CrossRef]

70. Stroud, D.A.; Surgenor, E.E.; Formosa, L.E.; Reljic, B.; Frazier, A.E.; Dibley, M.G.; Osellame, L.D.; Stait, T.; Beilharz, T.H.; Thorburn, D.R.; et al. Accessory subunits are integral for assembly and function of human mitochondrial complex I. Nature 2016, 538, 123. [CrossRef]

71. Quiros, P.M.; Prado, M.A.; Zamboni, N.; D'Amico, D.; Williams, R.W.; Finley, D.; Gygi, S.P.; Auwerx, J. Multi-omics analysis identifies ATF4 as a key regulator of the mitochondrial stress response in mammals. J. Cell Biol. 2017, 216, 2027-2045. [CrossRef] [PubMed]

72. Bragoszewski, P.; Gornicka, A.; Sztolsztener, M.E.; Chacinska, A. The ubiquitin-proteasome system regulates mitochondrial intermembrane space proteins. Mol. Cell. Biol. 2013, 33, 2136-2148. [CrossRef] [PubMed]

73. Wei, Y.; Vellanki, R.N.; Coyaud, E.; Ignatchenko, V.; Li, L.; Krieger, J.R.; Taylor, P.; Tong, J.; Pham, N.A.; Liu, G.; et al. CHCHD2 Is Coamplified with EGFR in NSCLC and Regulates Mitochondrial Function and Cell Migration. Mol. Cancer Res. 2015, 13, 1119-1129. [CrossRef] [PubMed]

74. Yagi, M.; Uchiumi, T.; Takazaki, S.; Okuno, B.; Nomura, M.; Yoshida, S.; Kanki, T.; Kang, D. p32/gC1qR is indispensable for fetal development and mitochondrial translation: Importance of its RNA-binding ability. Nucleic Acids Res. 2012, 40, 9717-9737. [CrossRef]

75. Lutas, A.; Wahlmark, C.J.; Acharjee, S.; Kawasaki, F. Genetic Analysis in Drosophila Reveals a Role for the Mitochondrial Protein P32 in Synaptic Transmission. G3-Genes Genom. Genet. 2012, 2, 59-69. [CrossRef] [PubMed]

76. Imai, Y. Mitochondrial Regulation by PINK1-Parkin Signaling. ISRN Cell Biol. 2012, 2012, 926160. [CrossRef]

77. Tanaka, A.; Cleland, M.M.; Xu, S.; Narendra, D.P.; Suen, D.F.; Karbowski, M.; Youle, R.J. Proteasome and p97 mediate mitophagy and degradation of mitofusins induced by Parkin. J. Cell Biol. 2010, 191, 1367-1380. [CrossRef] [PubMed]

78. Matsumoto, G.; Shimogori, T.; Hattori, N.; Nukina, N. TBK1 controls autophagosomal engulfment of polyubiquitinated mitochondria through p62/SQSTM1 phosphorylation. Human Mol. Genet. 2015, 24, 4429-4442. [CrossRef] [PubMed]

79. Richter, B.; Sliter, D.A.; Herhaus, L.; Stolz, A.; Wang, C.; Beli, P.; Zaffagnini, G.; Wild, P.; Martens, S.; Wagner, S.A.; et al. Phosphorylation of OPTN by TBK1 enhances its binding to Ub chains and promotes selective autophagy of damaged mitochondria. Proc. Natl. Acad. Sci. USA 2016, 113, 4039-4044. [CrossRef] [PubMed]

80. Guzman, J.N.; Sanchez-Padilla, J.; Wokosin, D.; Kondapalli, J.; Ilijic, E.; Schumacker, P.T.; Surmeier, D.J. Oxidant stress evoked by pacemaking in dopaminergic neurons is attenuated by DJ-1. Nature 2010, 468, 696-700. [CrossRef] [PubMed]

81. Burbulla, L.F.; Song, P.; Mazzulli, J.R.; Zampese, E.; Wong, Y.C.; Jeon, S.; Santos, D.P.; Blanz, J.; Obermaier, C.D.; Strojny, C.; et al. Dopamine oxidation mediates mitochondrial and lysosomal dysfunction in Parkinson's disease. Science 2017, 357, 1255-1261. [CrossRef] [PubMed]

82. Wang, W.; Wang, L.; Lu, J.; Siedlak, S.L.; Fujioka, H.; Liang, J.; Jiang, S.; Ma, X.; Jiang, Z.; da Rocha, E.L.; et al. The inhibition of TDP-43 mitochondrial localization blocks its neuronal toxicity. Nat. Med. 2016, 22, 869-878. [CrossRef] [PubMed]

83. Mao, C.; Wang, H.; Luo, H.; Zhang, S.; Xu, H.; Zhang, S.; Rosenblum, J.; Wang, Z.; Zhang, Q.; Tang, M.; et al. CHCHD10 is involved in the development of Parkinson's disease caused by CHCHD2 loss-of-function mutation p.T61I. Neurobiol. Aging 2018, 75, 38-41. [CrossRef] [PubMed]

(C) 2019 by the authors. Licensee MDPI, Basel, Switzerland. This article is an open access article distributed under the terms and conditions of the Creative Commons Attribution (CC BY) license (http://creativecommons.org/licenses/by/4.0/). 